\title{
三INTERF SPAÇ8
}

\section{ANÁLISE DO DESENVOLVIMENTO HUMANO DOS MUNICÍPIOS DO ESTADO DE MINAS GERAIS A PARTIR DA AVALIAÇÃO DE INDICADORES SOCIOECONÔMICOS}

\section{ANALYSIS OF HUMAN DEVELOPMENT OF MUNICIPALITIES IN THE STATE OF MINAS GERAIS FROM THE EVALUATION OF SOCIOECONOMIC INDICATORS}

\section{ANÁLISIS DEL DESARROLLO HUMANO DE LOS MUNICIPIOS DEL ESTADO DE MINAS GERAIS A PARTIR DE LA EVALUACIÓN DE INDICADORES SOCIOECONÓMICOS}

\author{
Éder de Souza Beirão \\ Mestre em Desenvolvimento Social pela Universidade Estadual de Montes Claros - \\ UNIMONTES. \\ ederbeirao@gmail.com / http:// orcid.org/0000-0003-4379-9345
}

Luíz Filipe Rodrigues dos Santos

Mestre em Desenvolvimento Social pela Universidade Estadual de Montes Claros UNIMONTES. filipesantis@hotmail.com / http://orcid.org/0000-0002-6379-6611

\section{Marcos Esdras Leite}

Doutor em Geografia pela Universidade Federal de Uberlândia - UFU. Professor do Departamento de Geociências e dos Programas de Pós-graduação em Geografia e em Desenvolvimento Social da Universidade Estadual de Montes Claros - UNIMONTES. marcosesdrasleite@gmail.com / http://orcid.org/0000-0002-9020-6445

Recebido para avaliação em 03/11/2019; Aceito para publicação em 05/12/2020.

\section{RESUMO}

O crescimento econômico está intimamente ligado ao desenvolvimento humano e da sociedade. Para que o progresso econômico ocorra de fato, é preciso que os problemas sociais sejam resolvidos, como é o caso da pobreza, fome, violência, falta de moradia, de acesso a serviços de saúde e educação etc. Sendo assim, o presente estudo tem como objetivo analisar o desenvolvimento humano dos municípios do estado de Minas Gerais a partir da avaliação de indicadores socioeconômicos. Por meio da avaliação do Índice de Desenvolvimento Humano Municipal (IDH-M) e suas dimensões, em conjunto com alguns indicadores socioeconômicos, foi possível chegar à conclusão de que a redução da renda per capita leva ao aumento da vulnerabilidade social e consequente elevação da desigualdade na distribuição de renda (concentração de renda), estes fatores interferem na qualidade de vida dos habitantes dos municípios do estado de Minas Gerais, principalmente no que tange às dimensões da saúde e educação, representadas pelo IDH-M Longevidade e Educação, respectivamente.

Palavras-chave: Desenvolvimento Humano; Crescimento Econômico; Índice de Desenvolvimento Humano Municipal; Indicadores Socioeconômicos; Minas Gerais. 
|Análise do desenvolvimento humano dos municípios do estado de Minas Gerais a partir da avaliação de indicadores socioeconômicos |

\section{|Éder de Souza Beirão | Luíz Filipe Rodrigues dos Santos | Marcos Esdras Leite |}

Economic growth is closely linked to human development and society. To make economic progress occur, it is necessary that social problems are solved, such as poverty, hunger, violence, lack of housing, access to health and education services, etc. Therefore, the present study aims to analyze the human development of the municipalities of the state of Minas Gerais through the evaluation of socioeconomic indicators. Through the evaluation of the MHDI and its dimensions, together with some socioeconomic indicators, it was possible to conclude that the reduction of per capita income leads to an increase in social vulnerability and a consequent increase of inequality in income distribution (concentration of income), these factors interfere in the quality of life of the inhabitants of the municipalities of the state of Minas Gerais, mostly regarding the dimensions of health and education, represented by the MHDI Longevity and Education, respectively.

Keywords: Human Development; Economic Growth; Municipal Human Development Index; Socioeconomic Indicators; Minas Gerais.

\section{RESUMEN}

El crecimiento económico está estrechamente vinculado al desarrollo humano y social. Para que se produzca el progreso económico, es necesario resolver problemas sociales como la pobreza, el hambre, la violencia, la falta de vivienda, el acceso a los servicios de salud y educación, etc. Por tanto, el presente estudio tiene como objetivo analizar el desarrollo humano de los municipios del estado de Minas Gerais a partir de la evaluación de indicadores socioeconómicos. A través de la evaluación del Índice de Desarrollo Humano Municipal (IDH-M) y sus dimensiones, junto con algunos indicadores socioeconómicos, se pudo llegar a la conclusión de que la reducción del ingreso per cápita conduce a un aumento de la vulnerabilidad social y un consecuente aumento de la desigualdad En la distribución del ingreso (concentración del ingreso), estos factores interfieren en la calidad de vida de los habitantes de los municipios del estado de Minas Gerais, principalmente en lo que se refiere a las dimensiones de salud y educación, representadas por el IDH-M Longevidad y Educación, respectivamente.

Palabras clave: Desarrollo Humano; Crecimiento Económico; Índice de Desarrollo Humano Municipal; Indicadores Socioeconómicos; Minas Gerais.

\section{INTRODUÇÃO}

O desenvolvimento humano vem ocupando cada vez mais o lugar central nas discussões sobre o desenvolvimento desde o início da década de 1990 (OLIVEIRA, 2002). O crescimento econômico vem perdendo sentido se este não consegue promover o desenvolvimento humano e social de uma determinada região (MARTINS, 2002).

No panorama do desenvolvimento econômico regional e local têm sido incorporadas questões políticas, ambientais, culturais e sociais. Assim, o desenvolvimento sustentável e pleno precisa buscar a redução da exclusão social e a promoção da preservação ambiental (MARTINS, 2002; OLIVEIRA, 2002).

O desenvolvimento deve resultar em crescimento econômico acompanhado da melhoria da qualidade de vida da coletividade, ou seja, deve promover alterações na composição do produto, na alocação de recursos pelos diferentes setores da economia e melhorar os indicadores de bem-estar social e econômico (desigualdade, desemprego, 
|Análise do desenvolvimento humano dos municípios do estado de Minas Gerais a partir da avaliação de indicadores socioeconômicos |

|Éder de Souza Beirão | Luíz Filipe Rodrigues dos Santos | Marcos Esdras Leite |

acesso a serviços de saúde, alimentação, educação, moradia e pobreza) (VASCONCELLOS; GARCIA, 1998).

Já que em meados dos anos 1990, a mudança de perspectiva acerca do desenvolvimento estava em curso, foi criado o Índice de Desenvolvimento Humano (IDH) que oferta um contraponto a um outro indicador muito utilizado na mensuração do desenvolvimento, o Produto Interno Bruto (PIB) per capita, que considera apenas a dimensão econômica do desenvolvimento (PNUD, 2019).

No Censo Demográfico do IBGE, realizado no ano 2000, o Brasil possuía um IDH de 0,612, o que o classificava como médio desenvolvimento humano. Já no ano 2010, o indicador se elevou para 0,727, expressando que o país passou a ter um alto desenvolvimento humano. Apesar de ser extremamente desigual, no ano de 2014, a situação melhorou, visto que o país passou a ocupar a $75^{a}$ posição no ranking global do IDH, com 0,755.

Dentre as unidades federativas do Brasil, Minas Gerais foi escolhido como objeto de estudo por ser o estado com o maior número de municípios do Brasil e por consequência possuir um alto contingente de municípios com extratos "muito baixo", "baixo" e "médio" do IDH e de suas dimensões, Longevidade, Renda e Educação. O IDH do estado de Minas Gerais ocupou a oitava e nona posições no âmbito do Brasil e, na Região Sudeste, encontra-se na última posição, tendo apresentado nos Censos Demográficos de 2000 e 2010 os valores de 0,624 e 0,731, respectivamente.

Por se tratar de dados municipais, este trabalho analisou além do Índice de Desenvolvimento Humano Municipal (IDH-M), o IDH-M Longevidade, IDH-M Educação e alguns indicadores socioeconômicos que são o PIB per capita (proxy de renda per capita e do IDH-M Renda), a porcentagem de indivíduos vulneráveis à pobreza e o coeficiente de Gini. Estes indicadores representam a qualidade de vida e foram em sua maioria disponibilizados no Atlas do Desenvolvimento Humano do Programa das Nações Unidas para o Desenvolvimento (PNUD), através de dados do Instituto de Pesquisas Econômicas Aplicadas (IPEA), e Fundação João Pinheiro (FJP). A partir da análise destes indicadores foi realizado um mapeamento dos municípios e um ranking dos dez melhores e os dez piores para o estado de Minas Gerais, com vistas a caracterizá-los e estabelecer uma comparação da evolução entre o Censo Demográfico do ano 2000 e 2010.

Considerando a importância da discussão acerca da avaliação de indicadores socioeconômicos e da promoção do desenvolvimento humano no âmbito dos municípios do estado de Minas Gerais, o presente estudo tem como questão-problema: é possível 
|Análise do desenvolvimento humano dos municípios do estado de Minas Gerais a partir da avaliação de indicadores socioeconômicos |

|Éder de Souza Beirão | Luíz Filipe Rodrigues dos Santos | Marcos Esdras Leite |

analisar o desenvolvimento humano dos municípios do estado de Minas Gerais a partir da avaliação de indicadores socioeconômicos?

$\mathrm{Na}$ busca de responder à questão norteadora traçada para o presente estudo, foi definido como objetivo geral: analisar o desenvolvimento humano dos municípios do estado de Minas Gerais, a partir da avaliação de indicadores socioeconômicos.

Para o desenvolvimento do trabalho ora apresentado adotou-se os seguintes procedimentos metodológicos: pesquisa, levantamento e seleção bibliográfica acerca da temática proposta, construção do banco de dados, elaboração dos produtos cartográficos e tabelas com rankings dos indicadores.

A fundamentação teórica encontra-se apoiada nas ideias de Celso Furtado (1974), Maria Cecília Prates Rodrigues (1993), Paulo Sandroni (1994), Juan Hersztajn Moldau (1998), Amartya Kumar Sen (2000 e 2001), Paulo de Martino Jannuzzi (2001 e 2012), Gilson Batista de Oliveira (2002), Dieter Rugard Siedenberg (2003), Rosemari Fátima Orlowski e Silvio Cezar Arend (2005), Márcio Andrade Monteiro (2008), Solange Ledi Gonçalves e Ana Flávia Machado (2013) e Severino Cesário de Lima e Josedilton Alves Diniz (2016) e outros autores que contribuíram significativamente para a discussão aqui proposta.

\section{DESENVOLVIMENTO HUMANO COMO ALTERNATIVA AO DESENVOLVIMENTO ECONÔMICO}

Um dos questionamentos mais fundamental no estudo do desenvolvimento é da possibilidade de universalizar o desenvolvimento capitalista ocidental para os países periféricos. Furtado (1974) discutiu e apontou essa possibilidade enquanto um mito.

A literatura que trata do desenvolvimento econômico afirma que o que vêm sendo praticado pelos países que lideraram a Revolução Industrial, pode ser universalizado, ou seja, a pretensão é que os padrões de consumo da minoria da humanidade, que atualmente vive nos países industrializados, são acessíveis à grande maioria da população em rápida expansão que formam os chamados países de Terceiro Mundo, atualmente conhecidos como subdesenvolvidos. Essa ideia diz respeito a uma prolongação do mito do progresso, elemento essencial na ideologia da revolução burguesa, dentro da qual foi criada a atual sociedade industrial (FURTADO, 1974).

Ao conceber este mito do progresso, os economistas privilegiaram o processo de acumulação de capital e deram pouca ou nenhuma atenção às consequências dessa escolha no plano social, econômico, ambiental, cultural etc. Isso é possível observar, uma vez que 
|Análise do desenvolvimento humano dos municípios do estado de Minas Gerais a partir da avaliação de indicadores socioeconômicos |

|Éder de Souza Beirão | Luíz Filipe Rodrigues dos Santos | Marcos Esdras Leite |

as grandes metrópoles sofrem com a poluição, aumento da violência e a criminalidade, os serviços públicos foram deteriorados, a fuga da juventude na anticultura e outros grandes problemas socioeconômicos. Essas e outras consequências tornaram-se um pesadelo para os acumuladores de capital que tinham em mente o tão sonhado "progresso" divulgado pelos teóricos do desenvolvimento econômico. Menos atenção ainda se havia dado ao impacto dessas mudanças no meio físico de um sistema de decisões cujos objetivos últimos eram e continuam sendo a satisfação dos interesses privados dos donos do capital (FURTADO, 1974).

Por isso, Furtado (1974, p. 75) afirmou que:

\begin{abstract}
A ideia de desenvolvimento econômico é um simples mito. Graças a ela tem sido possível desviar as atenções da tarefa básica de identificação das necessidades fundamentais da coletividade e das possibilidades que abrem ao homem os avanços da ciência, para concentrá-las em objetivos abstratos como são os investimentos, as exportações e o crescimento.
\end{abstract}

O crescimento econômico necessita de sentido, caso contrário o mesmo não consegue cumprir suas funções e em última instância, pode ficar impossibilitado de promover o desenvolvimento humano e social, ao atender e satisfazer as necessidades da população de uma determinada região/país (RODRIGUES, 1993).

Depois de ter ficado por tanto tempo tentando promover o crescimento econômico, esta estratégia tem se provado cada vez menos eficiente. Hoje em dia, pensa-se cada vez mais como as pessoas são afetadas pelo processo de crescimento, ou seja, se os incrementos positivos no produto e na renda total estão sendo destinados ou utilizados para a promoção do desenvolvimento humano (OLIVEIRA, 2002).

Atualmente, não se leva em consideração apenas as variações do Produto Interno Bruto (PIB) do período anterior. Sandroni (1994) já levava em consideração o desenvolvimento econômico como crescimento econômico (incrementos positivos no PIB) acompanhado de melhorias do nível de vida dos cidadãos e por alterações estruturais na economia.

Lentamente essas perspectivas têm sido mudadas. A dimensão social do desenvolvimento tem se tornado fundamental, pois é cada vez mais importante que as necessidades dos indivíduos sejam atendidas e que as crianças, adolescentes e jovens tenham acesso à educação, à saúde e a uma moradia digna, enfim, que estes possam desfrutar uma longa vida produtiva que lhes permita manter uma família (PNUD, 1996).

Neste caso, atender às necessidades da coletividade e atingir o tão almejado desenvolvimento humano significa reduzir a exclusão social, que é caracterizada pela 
|Análise do desenvolvimento humano dos municípios do estado de Minas Gerais a partir da avaliação de indicadores socioeconômicos |

|Éder de Souza Beirão | Luíz Filipe Rodrigues dos Santos | Marcos Esdras Leite |

pobreza e desigualdade (OLIVEIRA, 2002). O problema da desigualdade está atrelado não somente à insuficiência de renda, mas principalmente à distribuição de liberdades substantivas e capacidades (SEN, 2000).

A distribuição de liberdades substantivas e capacidades expressam uma ideia de igualdade de oportunidades e valorizam as liberdades das pessoas para levarem a vida da maneira que quiserem e lutarem pelo alcance de seus objetivos (SEN, 2001). Logo se os indivíduos de uma determinada localidade não dispõem de uma adequada distribuição de liberdades substantivas e capacidades para realizar suas escolhas, suas oportunidades e recursos serão mais escassos, realizações menos expressivas e menor será o seu bem-estar social e desenvolvimento humano.

$\mathrm{Na}$ década de 1990, Mahbub ul Haq em colaboração com Amartya Sen, desenvolveram o Índice de Desenvolvimento Humano (IDH) (PNUD, 2019). O IDH é um indicador socioeconômico fundamental que apresenta a mensuração quantitativa do desenvolvimento humano no Brasil e no mundo.

O IDH tem o objetivo avaliar a qualidade de vida nos países. Em seu cálculo estão inclusas as variáveis saúde, educação e renda per capita, que variam entre zero e um. A partir dessa variação é possível classificar os países em três grupos: os de baixo desenvolvimento (IDH menor do que 0,5); os de médio desenvolvimento (IDH entre 0,5 e 0,8); e os de alto desenvolvimento (IDH maior do que 0,8) (GONÇALVES; MACHADO, 2013).

De forma simplificada, o IDH trata da longevidade (esperança de vida ao nascer), renda (PIB per capita) e educação (taxa de matrícula e alfabetização) de uma determinada localidade/região (MINAYO; HARTZ; BUSS, 2000). Almeida e Oliveira (2016), por sua vez, afirmam que a medida das dimensões do IDH é construída a partir dos seguintes fatores:

- Longevidade: Esta diz respeito ao gozo de uma vida saudável e longa, ou seja, uma vida com saúde e é mensurada pela expectativa de vida;

- Renda: Esta é medida pela Renda Nacional Bruta (RNB) per capita;

- Educação: O acesso aos serviços de educação é mensurado pelos seguintes aspectos: i) média de anos de educação de adultos; ii) expectativa de anos de escolaridade de crianças que estão aptos à ingressão na vida escolar.

Como já fora mencionado, o IDH e suas dimensões variam de 0 a 1 , de tal maneira que, quanto mais próximo o resultado do indicador estiver de 1 , maior é o desenvolvimento humano (MONTEIRO, 2008). A fórmula do IDH (Fórmula 1) é a seguinte: 
|Análise do desenvolvimento humano dos municípios do estado de Minas Gerais a partir da avaliação de indicadores socioeconômicos |

|Éder de Souza Beirão | Luíz Filipe Rodrigues dos Santos | Marcos Esdras Leite |

$$
I D H=\frac{I D H_{S}+I D H_{E}+I D H_{R}}{3}
$$

onde: $\mathrm{IDH}_{\mathrm{S}}$ representa o índice de vida saudável (longevidade); $\mathrm{IDH}_{\mathrm{E}}$ é o índice de acesso à educação e cultura; e $\mathrm{IDH}_{\mathrm{R}}$ é o índice de padrão de renda adequado de vida.

Para a realização do cálculo do $\mathrm{IDH}_{\mathrm{S}}, \mathrm{IDH}_{\mathrm{E}}$ e do $\mathrm{IDH}_{\mathrm{R}}$ faz-se necessária à adoção de um procedimento de normalização para que os valores dos indicadores variem de 0 a 1 (MONTEIRO, 2008). Para realizar tal procedimento é preciso considerar que o indicador $x$ varia de $x_{\text {min }}$ (valor mínimo) para $\chi_{\max }$ (valor máximo). Este procedimento é realizado pela Fórmula 2, a saber:

$$
x_{\text {norm }}=x-x_{\min } / x_{\max }+x_{\min }
$$

Somados a estes indicadores, o IDH, bem como, seus subíndices ou dimensões, longevidade, renda e educação, o presente trabalho avaliou outros indicadores socioeconômicos. Estes indicadores se constituem um importante instrumento de suporte à elaboração de políticas públicas, podendo assim estimular fatores positivos, e, na oportunidade, perceber os fatores negativos que obstruem o desenvolvimento de uma determinada região e, com base nisso, agir para minimizá-los ou suprimi-los (ORLOWSKI; AREND, 2005).

Os indicadores sociais tornam possível a mensuração da realidade de um município, permitindo assim que sejam traçadas e implementadas políticas públicas mais acertadas (JANUZZI, 2012). Além disso, através da avaliação destes indicadores é possível analisar a situação e a evolução de uma sociedade em seus vários aspectos (MOLDAU, 1998).

Estes indicadores são compostos de variáveis sociais e econômicas e possuem o objetivo de mensurar as necessidades da população. Estas necessidades podem estar ligadas a questões de renda, mercado de trabalho, transporte público, índice de mortalidade e natalidade, analfabetismo, acesso a serviços de saúde, coleta de lixo etc. (LIMA; DINIZ, 2016).

Os indicadores sociais e econômicos devem ser utilizados para a análise e avaliação de pontos fracos e fortes, mas também para avaliar o sucesso ou fracasso de estratégias de gestão ou de desenvolvimento de uma determinada cidade ou região (SIEDENBERG, 2003). A utilização destes indicadores em séries históricas é necessária para tornar possíveis análises e comparações inter-regionais ou intrarregionais e a evolução em termos temporais (JANNUZZI, 2001). 
|Análise do desenvolvimento humano dos municípios do estado de Minas Gerais a partir da avaliação de indicadores socioeconômicos |

|Éder de Souza Beirão | Luíz Filipe Rodrigues dos Santos | Marcos Esdras Leite |

No entanto, a utilização de cada indicador depende do modelo aceito para descrever o fenômeno a ser analisado (MOLDAU, 1998). Portanto, faz-se necessário verificar quais, dentre a vasta gama de opções de indicadores, atende às necessidades de um determinado estudo. No caso deste, como já fora explicitado, os indicadores que deram suporte à análise foram o PIB per capita, coeficiente de Gini e porcentagem de indivíduos vulneráveis à pobreza.

\section{BREVE CARACTERIZAÇÃO DO ESTADO DE MINAS GERAIS}

O estado de Minas Gerais é uma das 27 unidades federativas existentes no Brasil, integrante da região sudeste, sendo este o quarto maior em extensão territorial e o segundo em número de habitantes, sendo superado apenas por São Paulo. Limita-se ao sul e sudoeste com o estado de São Paulo, a oeste com Mato Grosso do Sul, a norte e nordeste com o estado da Bahia, a leste com o Espírito Santo e a sudeste com o Rio de Janeiro e a noroeste com Goiás e o Distrito Federal. A Figura 1 apresenta o mapa de localização do estado de Minas Gerais.

Figura 1 - Mapa de localização do estado de Minas Gerais.

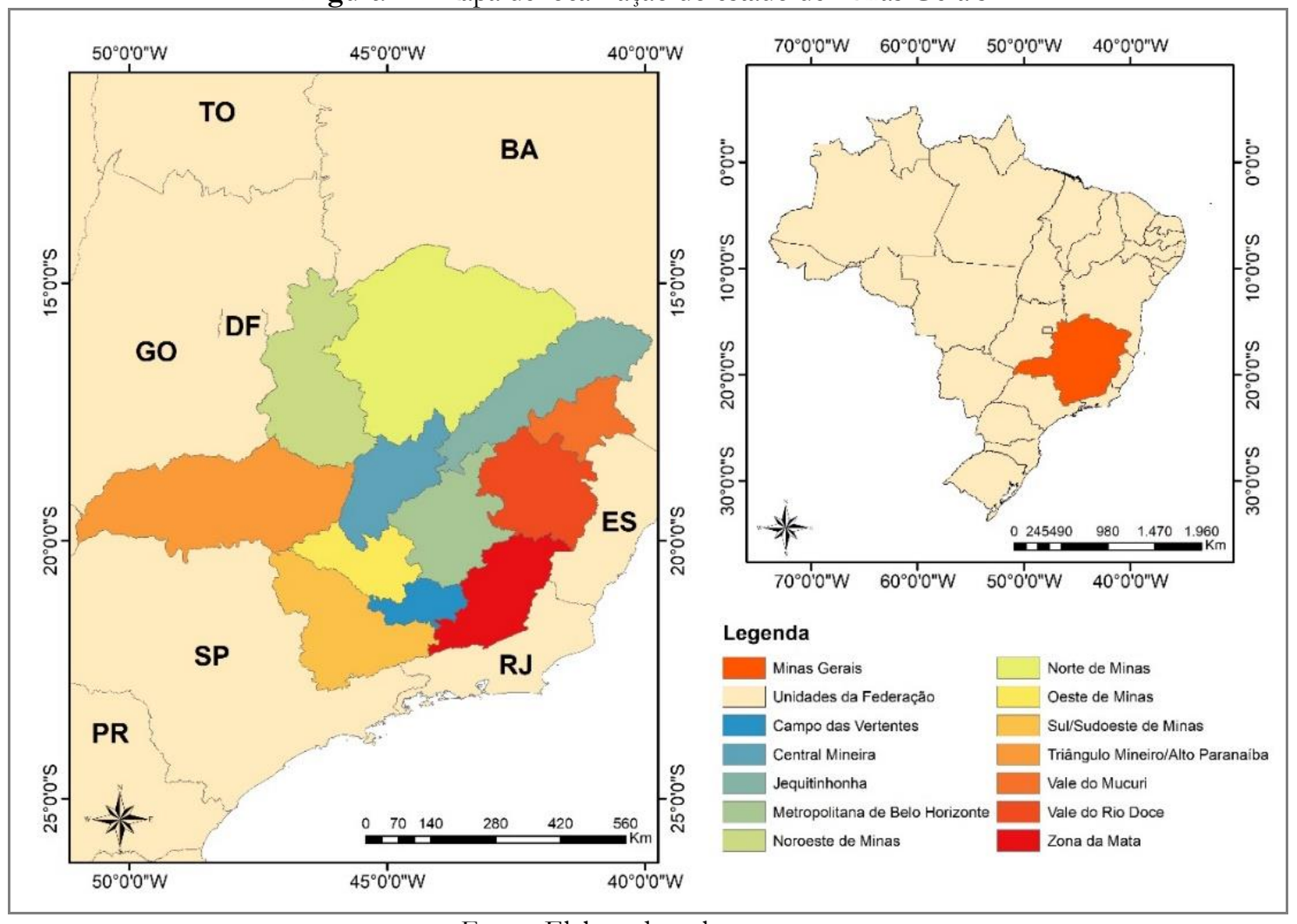

Fonte: Elaborado pelos autores. 
| Análise do desenvolvimento humano dos municípios do estado de Minas Gerais a partir da avaliação de indicadores socioeconômicos |

|Éder de Souza Beirão | Luíz Filipe Rodrigues dos Santos | Marcos Esdras Leite |

Minas Gerais possui área total de 586.522,122 $\mathrm{km}^{2}$, estimativa populacional de 21.119.536 habitantes, densidade demográfica de 36,01 hab. $/ \mathrm{km}^{2}$, Produto Interno Bruto (PIB) per capita de $\mathrm{R} \$ 17.931,00$, posicionando-se na décima posição em termos de crescimento econômico, clima tropical e tropical de altitude e tem como capital o município de Belo Horizonte.

O território do estado é divido em 853 municípios que são subdivididos nas mesorregiões de Campos das Vertentes, Central Mineira, Jequitinhonha, Metropolitana de Belo Horizonte, Noroeste de Minas, Norte de Minas, Oeste de Minas, Sul e Sudoeste de Minas, Triângulo Mineiro e Alto Paranaíba, Vale do Mucuri, Vale do Rio Doce e Zona da Mata.

\section{PROCEDIMENTOS METODOLÓGICOS}

Com o intuito de atender ao objetivo traçado para este estudo, foi realizada uma pesquisa de abordagem quantitativa. Quanto aos objetivos, a pesquisa classifica-se em descritiva e exploratória. Quanto aos procedimentos técnicos, a pesquisa é classificada como bibliográfica e documental. O método de pesquisa utilizado foi o estudo de caso, sendo que o recorte do trabalho são os municípios do estado de Minas Gerais, tendo como amostra os Municípios da referida unidade federativa. A amostra em questão pode ser classificada como não probabilística.

O instrumento de coleta de dados utilizado foi o levantamento dos dados referentes aos indicadores socioeconômicos dos municípios do estado de Minas Gerais, disponível nas plataformas Atlas do Desenvolvimento Humano do Brasil do Programa das Nações Unidas para o Desenvolvimento (PNUD) e o Índice Mineiro de Responsabilidade Social (IMRS) da Fundação João Pinheiro (FJP). Os indicadores socioeconômicos coletados dessas plataformas foram os seguintes, a saber: i) Renda per capita; ii) Porcentagem de indivíduos vulneráveis à pobreza; iii) Coeficiente de Gini; iv) IDH-M; v) IDH-M Longevidade; e vi) IDH-M Educação. O primeiro deles foi obtido na plataforma do IMRS/FJP e os demais no Atlas do Desenvolvimento Humano do PNUD.

Para a construção do banco de dados foi utilizado o software Microsoft Excel e para a elaboração dos produtos cartográficos o software ArcGIS 10.5. Além dos mapas foram elaboradas tabelas com rankings dos 10 municípios com maiores e menores indicadores para cada um dos indicadores socioeconômicos analisados nos anos 2000 e 2010.

\section{ANÁLISE E DISCUSSÃO DE RESULTADOS}


|Análise do desenvolvimento humano dos municípios do estado de Minas Gerais a partir da avaliação de indicadores socioeconômicos |

|Éder de Souza Beirão | Luíz Filipe Rodrigues dos Santos | Marcos Esdras Leite |

Esta seção se ocupa de avaliar o desempenho dos indicadores socioeconômicos com o intuito de analisar o desenvolvimento humano dos municípios do estado de Minas Gerais. Como já fora explicitado, os dados foram obtidos no Atlas de Desenvolvimento Humano do PNUD e na FJP.

$\mathrm{Na}$ análise deste e dos outros indicadores foi elaborado um ranking com dez municípios piores e melhores para os anos 2000 e 2010, seguida de uma análise espacial dos municípios graduado em níveis para o indicador.

O primeiro indicador analisado é o da renda per capita, representado por uma variável proxy, o PIB per capita. A renda per capita corresponde ao resultado obtido pela divisão da renda de todos os habitantes que residiam em domicílios particulares permanentes e o número total destes indivíduos e, por isso, constitui-se como um valor médio. Os valores foram ajustados monetariamente em reais de agosto de 2010 (ATLAS DE DESENVOLVIMENTO HUMANO, 2013). Neste caso, por se tratar de variável proxy, trata-se da razão entre o PIB per capita, o número de indivíduos que residem em domićlios particulares permanentes e o número total de habitantes do estado de Minas Gerais nos anos 2000 e 2010. A Tabela 01 apresenta o ranking das menores rendas per capitas dos municípios do estado de Minas Gerais nos anos 2000 e 2010.

Tabela 01 - Ranking das menores rendas per capitas dos municípios do estado de Minas Gerais nos anos 2000 e 2010.

\begin{tabular}{l|r|l|r}
\hline \multicolumn{1}{c|}{ Município } & \multicolumn{1}{c|}{$\mathbf{R P C} / \mathbf{2 0 0 0}$} & \multicolumn{1}{c|}{ Município } & RPC/2010 \\
\hline São João das Missões & $\mathrm{R} \$ 1.005,31$ & São João das Missões & $\mathrm{R} \$ 3.250,00$ \\
\hline Santo Antônio do Retiro & $\mathrm{R} \$ 1.039,77$ & Francisco Badaró & $\mathrm{R} \$ 3.390,96$ \\
\hline Setubinha & $\mathrm{R} \$ 1.070,34$ & Chapada do Norte & $\mathrm{R} \$ 3.504,26$ \\
\hline Lontra & $\mathrm{R} \$ 1.092,99$ & Bonito de Minas & $\mathrm{R} \$ 3.513,40$ \\
\hline Bonito de Minas & $\mathrm{R} \$ 1.095,96$ & Lontra & $\mathrm{R} \$ 3.516,87$ \\
\hline Chapada do Norte & $\mathrm{R} \$ 1.110,31$ & Riacho dos Machados & $\mathrm{R} \$ 3.614,27$ \\
\hline Japonvar & $\mathrm{R} \$ 1.125,52$ & Malacacheta & $\mathrm{R} \$ 3.637,87$ \\
\hline Monte Formoso & $\mathrm{R} \$ 1.136,59$ & Palmópolis & $\mathrm{R} \$ 3.638,82$ \\
\hline Miravânia & $\mathrm{R} \$ 1.152,13$ & Monte Formoso & $\mathrm{R} \$ 3.646,65$ \\
\hline Ladainha & $\mathrm{R} \$ 1.166,95$ & Novo Cruzeiro & $\mathrm{R} \$ 3.667,20$ \\
\hline
\end{tabular}

Fonte: Elaborado pelos autores com base nos dados da FJP (2010).

A Tabela 02 apresenta o ranking das maiores rendas per capitas dos municípios do estado de Minas Gerais nos anos 2000 e 2010.

Tabela 02 - Ranking das maiores rendas per capitas dos municípios do estado de Minas Gerais nos anos 2000

\begin{tabular}{l|c|l|r}
\multicolumn{1}{c|}{ Município } & RPC $/ \mathbf{2 0 0 0}$ & \multicolumn{1}{c}{ Município } & RPC $/ 2010$ \\
\hline Araporã & $\mathrm{R} \$ 63.040,49$ & São Gonçalo do Rio Abaixo & $\mathrm{R} \$ 199.513,63$ \\
\hline Fronteira & $\mathrm{R} \$ 39.013,80$ & Araporã & $\mathrm{R} \$ 159.815,65$ \\
\hline Pirajuba & $\mathrm{R} \$ 28.399,64$ & Itatiaiuçu & $\mathrm{R} \$ 98.177,11$ \\
\hline Tapira & $\mathrm{R} \$ 27.238,31$ & Confins & $\mathrm{R} \$ 97.786,45$ \\
\hline
\end{tabular}


|Análise do desenvolvimento humano dos municípios do estado de Minas Gerais a partir da avaliação de indicadores socioeconômicos |

|Éder de Souza Beirão | Luíz Filipe Rodrigues dos Santos | Marcos Esdras Leite |

\begin{tabular}{l|l|l|r}
\hline Indianópolis & $\mathrm{R} \$ 26.262,35$ & São José da Barra & $\mathrm{R} \$ 93.740,16$ \\
\hline Fortaleza de Minas & $\mathrm{R} \$ 25.995,03$ & Maria da Fé & $\mathrm{R} \$ 68.110,53$ \\
\hline Betim & $\mathrm{R} \$ 24.831,11$ & Nova Lima & $\mathrm{R} \$ 66.318,77$ \\
\hline São José da Barra & $\mathrm{R} \$ 20.726,60$ & Fortaleza de Minas & $\mathrm{R} \$ 66.280,07$ \\
\hline São João Batista do Glória & $\mathrm{R} \$ 20.304,84$ & Extrema & $\mathrm{R} \$ 65.983,88$ \\
\hline Planura & $\mathrm{R} \$ 19.211,47$ & Betim & $\mathrm{R} \$ 61.939,08$ \\
\hline
\end{tabular}

Fonte: Elaborado pelos autores com base nos dados da FJP (2010).

Conforme a Tabela 02, ocorreram poucas mudanças entre as dez piores rendas per capitas municipais de Minas Gerais, pois o município de São João das Missões/MG se destacou nos anos 2000 e 2010 por apresentar o pior desempenho nesse indicador, com valores de $\mathrm{R} \$ 1.005,31$ e $\mathrm{R} \$ 3.250,00$, respectivamente. Apesar deste fato, os municípios mineiros experimentaram um crescimento significativo de suas rendas per capitas.

Muitas cidades se repetem no ranking dos municípios com menor renda per capita do estado de Minas Gerais dos anos 2000 e 2010, dentre eles, São João das Missões/MG, Lontra/MG, Bonito de Minas/MG, Chapada do Norte/MG e Monte Formoso/MG. Apesar disso, com exceção do município de São João das Missões/MG, todos os outros mudaram de posição no intervalo do ano 2000 para o ano 2010. No ano 2000, Lontra/MG, Bonito de Minas/MG, Chapada do Norte/MG e Monte Formoso/MG ocupavam a quarta, quinta, sexta e oitava posição, respectivamente, entre os municípios de menor renda per capita. Já no ano 2010, os mesmos municípios ocuparam a quinta, quarta, terceira e nona posições, respectivamente.

No intervalo entre os anos 2000 e 2010 ocorreram algumas repetições no ranking dos municípios com maior renda per capita do estado de Minas Gerais, dentre eles, Araporã/MG, Fortaleza de Minas/MG e São José da Barra/MG. Estes municípios mudaram de posição neste intervalo de tempo, tendo ocupado no ano 2000, a primeira, sexta e oitava posições, e no ano 2010, passaram a ocupar a segunda, oitava e quinta posições, respectivamente.

Para compreender melhor como encontra-se distribuído espacialmente a renda per capita municipal mineiro, a Figura 2 apresenta a renda per capita dos municípios do estado de Minas Gerais nos anos 2000 e 2010. 
| Análise do desenvolvimento humano dos municípios do estado de Minas Gerais a partir da avaliação de indicadores socioeconômicos |

|Éder de Souza Beirão | Luíz Filipe Rodrigues dos Santos | Marcos Esdras Leite |

Figura 2 - Renda per capita dos municípios do estado de Minas Gerais nos anos 2000 e 2010.

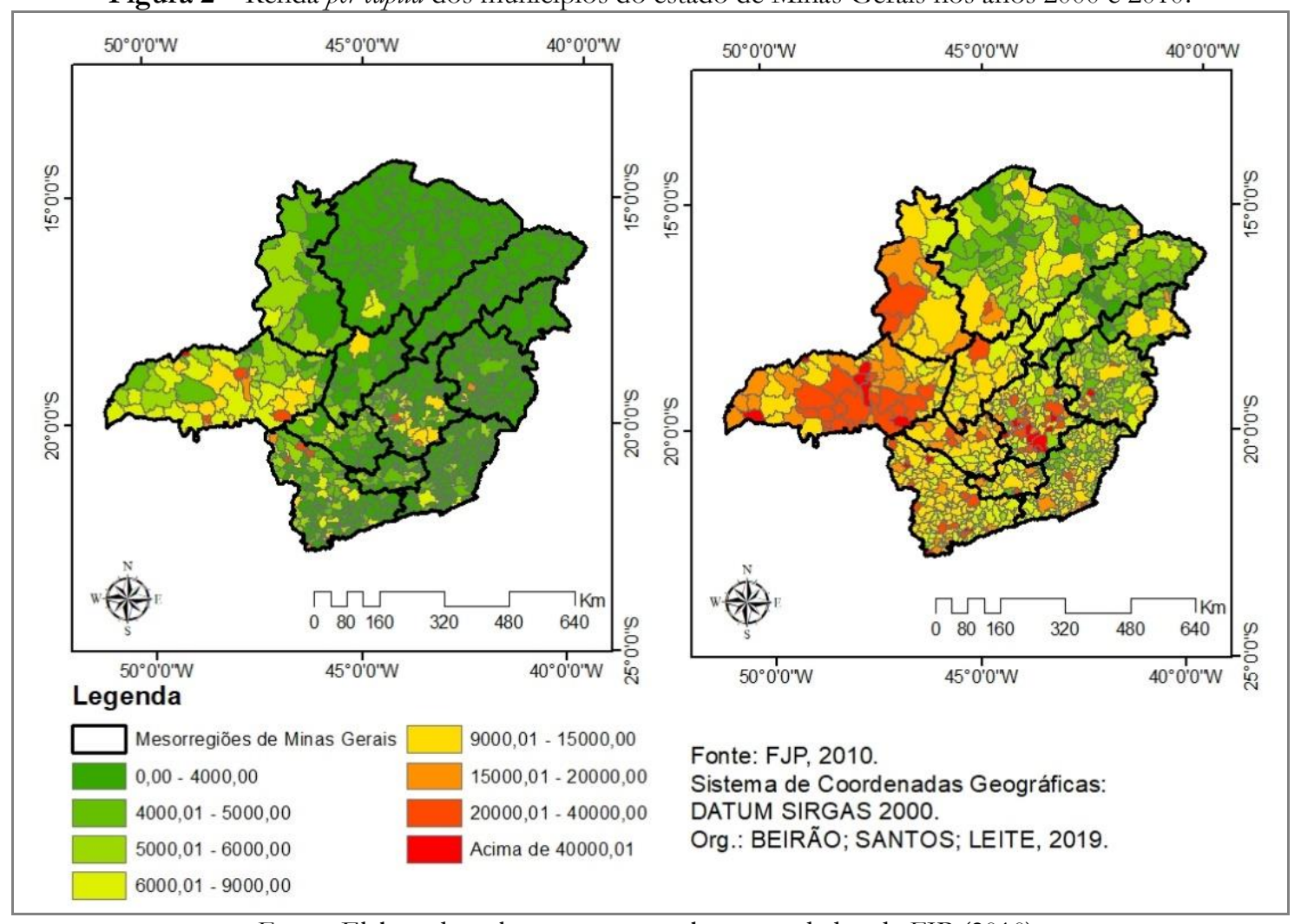

Fonte: Elaborado pelos autores com base nos dados da FJP (2010).

A partir da análise da Figura 2 é possível observar que houve uma melhora na renda per capita dos municípios do estado de Minas Gerais entre os anos 2000 e 2010, visto que, no ano do primeiro período, a concentração de municípios com menor renda localizava-se nas mesorregiões Jequitinhonha, Norte de Minas, Vale do Mucuri e Vale do Rio Doce. Já no ano 2010 houve uma redução desta concentração, uma vez que os municípios de menor rendimento per capita encontram-se distribuídos de forma dispersa no mapa. Além disso, pode-se observar a existência de uma concentração territorial dos municípios de melhor renda nas mesorregiões Central Mineira, Metropolitana de Belo Horizonte, Triângulo Mineiro/Alto Paranaíba, Sul/Sudoeste de Minas e Zona da Mata nos anos 2000 e 2010.

Ocorre que a insuficiência de renda define a existência da pobreza, principalmente quando se tem a finalidade de construir indicadores, porém os pobres são submetidos a privações em várias outras dimensões que não a renda. A pobreza seria a privação das capacidades básicas, podendo ser traduzida em um ou vários dos aspectos seguintes, a saber: morte prematura, subnutrição, alto grau de morbidade, analfabetismo, falta de liberdade de expressão ou participação da sociedade (ausência de democracia) e etc. (SEN, 2000).

A pobreza não tem como causa única o fato de o cidadão possuir baixa renda ou a inexistência dela (SEN, 2000). Apesar disso, a renda funciona como um bom indicador de 
|Análise do desenvolvimento humano dos municípios do estado de Minas Gerais a partir da avaliação de indicadores socioeconômicos |

|Éder de Souza Beirão | Luíz Filipe Rodrigues dos Santos | Marcos Esdras Leite |

bem-estar, e por isso se correlaciona com as privações nas demais dimensões ou, por vezes, pode ser considerada sua principal causa. Ocorre que a partir da renda é possível presumir a existência de privações. Isto se deve à multidimensionalidade do conceito de pobreza que se utiliza de um conjunto de indicadores de várias dimensões do bem-estar, calculados para indivíduos de distintas faixas de renda, ao invés de utilizar um indicador que condense as variadas situações que se apresentam em um único indicador (OSÓRIO et al., 2011).

O perfil de pobreza do Brasil, especialmente a do estado de Minas Gerais, pode ser avaliado de várias formas. Existem alguns dos indicadores do bloco da "Renda" do Atlas do Desenvolvimento Humano do PNUD, IPEA, IBGE e FJP. O Atlas, na busca de padronizar a avaliação e mensuração do perfil de pobreza do Brasil, definiu que existem três estratos de renda/pobreza, sendo eles: (1) proporção de extremamente pobres; (2) proporção de pobres; e (3) proporção de vulneráveis à pobreza. Em Minas Gerais existe uma altíssima concentração de renda e um número significativo de municípios com rendas per capitas inferiores à média do estado e, por este motivo, este estudo se utilizará de um único indicador, a porcentagem de indivíduos vulneráveis à pobreza dos municípios do estado de Minas Gerais nos anos 2000 e 2010.

A estatística de vulneráveis à pobreza diz respeito à proporção de indivíduos que possuem renda domiciliar per capita igual ou inferior a $\mathrm{R} \$ 255,00$ mensais, ajustado monetariamente em reais de agosto de 2010, equivalente a meio (1/2) salário mínimo neste mesmo ano. $\mathrm{O}$ contingente de indivíduos é limitado àqueles que residem em domicílios particulares (ATLAS DO DESENVOLVIMENTO HUMANO, 2013). A Tabela 03 apresenta o ranking das menores porcentagens de indivíduos vulneráveis à pobreza dos municípios do estado de Minas Gerais nos anos 2000 e 2010.

Tabela 03 - Ranking das menores porcentagens de indivíduos vulneráveis à pobreza dos municípios do estado de Minas Gerais nos anos 2000 e 2010.

\begin{tabular}{l|r|l|r}
\hline \multicolumn{1}{c|}{ Município } & PIVAP/2000 & \multicolumn{1}{|c}{ Município } & PIVAP/2010 \\
\hline Montes Claros & $21,32 \%$ & Nova Serrana & $10,77 \%$ \\
\hline Poços de Caldas & $22,05 \%$ & Perdigão & $10,99 \%$ \\
\hline Uberaba & $26,13 \%$ & Uberlândia & $12,41 \%$ \\
\hline Belo Horizonte & $26,91 \%$ & Araxá & $12,91 \%$ \\
\hline Andradas & $27,19 \%$ & Poços de Caldas & $13,21 \%$ \\
\hline Uberlândia & $27,45 \%$ & Montes Claros & $13,58 \%$ \\
\hline Jacutinga & $27,51 \%$ & Divinópolis & $13,60 \%$ \\
\hline Pouso Alegre & $27,85 \%$ & Uberaba & $13,63 \%$ \\
\hline Nova Serrana & $28,21 \%$ & Andradas & $13,64 \%$ \\
\hline Varginha & $28,97 \%$ & Nova Lima & $13,67 \%$ \\
\hline \multicolumn{2}{r|}{ Fonte: Elaborado pelos autores com base nos dados do Atlas do Desenvolvimento Humano $(2013)}$.
\end{tabular}

Fonte: Elaborado pelos autores com base nos dados do Atlas do Desenvolvimento Humano (2013). 
| Análise do desenvolvimento humano dos municípios do estado de Minas Gerais a partir da avaliação de indicadores socioeconômicos |

|Éder de Souza Beirão | Luíz Filipe Rodrigues dos Santos | Marcos Esdras Leite |

A Tabela 04 apresenta o ranking das maiores porcentagens de indivíduos vulneráveis à pobreza dos municípios do estado de Minas Gerais nos anos 2000 e 2010.

Tabela 04 - Ranking das maiores porcentagem de indivíduos vulneráveis à pobreza dos municípios do estado de Minas Gerais nos anos 2000 e 2010.

\begin{tabular}{l|r|l|r}
\hline \multicolumn{1}{c|}{ Município } & PIVAP/2000 & \multicolumn{1}{c|}{ Município } & PIVAP/2010 \\
\hline São João das Missões & $91,06 \%$ & Santo Antônio do Retiro & $78,40 \%$ \\
\hline Bonito de Minas & $91,04 \%$ & Monte Formoso & $78,16 \%$ \\
\hline Monte Formoso & $90,83 \%$ & Bonito de Minas & $78,09 \%$ \\
\hline Verdelândia & $90,57 \%$ & São João das Missões & $77,31 \%$ \\
\hline Cônego Marinho & $90,21 \%$ & Cristália & $76,64 \%$ \\
\hline Fronteira dos Vales & $90,15 \%$ & Setubinha & $75,55 \%$ \\
\hline Comercinho & $89,89 \%$ & Ninheira & $74,12 \%$ \\
\hline Santa Cruz de Salinas & $89,83 \%$ & Pains & $74,10 \%$ \\
\hline Matias Cardoso & $89,78 \%$ & Catuji & $74,03 \%$ \\
\hline Francisco Sá & $89,72 \%$ & Santa Helena de Minas & $73,99 \%$ \\
\hline
\end{tabular}

Fonte: Elaborado pelos autores com base nos dados do Atlas do Desenvolvimento Humano (2013).

Conforme a Tabela 4, ocorreram poucas mudanças entre os dez municípios com menor número de indivíduos vulneráveis à pobreza de Minas Gerais. Muitas das cidades se repetiram no ranking dos municípios com menor porcentagem de indivíduos vulneráveis à pobreza em Minas Gerais nos anos 2000 e 2010, dentre eles, Montes Claros/MG, Poços de Caldas/MG, Uberaba/MG, Andradas/MG, Uberlândia/MG e Nova Serrana/MG. Apesar disso, todos os outros mudaram de posição no intervalo do ano 2000 para o ano 2010. No ano 2000, estes municípios ocupavam a primeira, segunda, terceira, quinta, sexta e nona posição, respectivamente, entre os municípios com menores porcentagens de indivíduos em condição de pobreza. Já no ano 2010, os mesmos municípios ocuparam a sexta, quinta, oitava, nona, terceira e primeira posições, respectivamente. Os municípios do estado de Minas Gerais, no geral, conseguiram reduzir a porcentagem de indivíduos vulneráveis à condição de pobreza.

No intervalo entre os anos 2000 e 2010 ocorreu uma repetição no ranking dos municípios com maior porcentagem de indivíduos vulneráveis à pobreza do estado de Minas Gerais, dentre eles, São João das Missões/MG, Bonito de Minas/MG e Monte Formoso/MG. Estes municípios mudaram de posição neste intervalo de tempo, tendo ocupado no ano 2000, a primeira, segunda e terceira posições, e no ano 2010, passaram a ocupar a quarta, terceira e segunda posições, respectivamente.

O ranking da porcentagem de indivíduos vulneráveis à pobreza corresponde fielmente à renda per capita visto anteriormente; pois no 2000 a menor renda per capita foi do município de São João das Missões/MG, correspondendo ao município com maior porcentagem de indivíduos vulneráveis à pobreza. Os municípios com maior renda per 
|Análise do desenvolvimento humano dos municípios do estado de Minas Gerais a partir da avaliação de indicadores socioeconômicos |

|Éder de Souza Beirão | Luíz Filipe Rodrigues dos Santos | Marcos Esdras Leite |

capita, por sua vez, não correspondem aos municípios com menor porcentagem de indivíduos vulneráveis à condição da pobreza. A Figura 3 apresenta a porcentagem de indivíduos vulneráveis à pobreza dos municípios do estado de Minas Gerais nos anos 2000 e 2010.

Figura 3 - Porcentagem de indivíduos vulneráveis à pobreza dos municípios do estado de Minas Gerais nos anos 2000 e 2010.

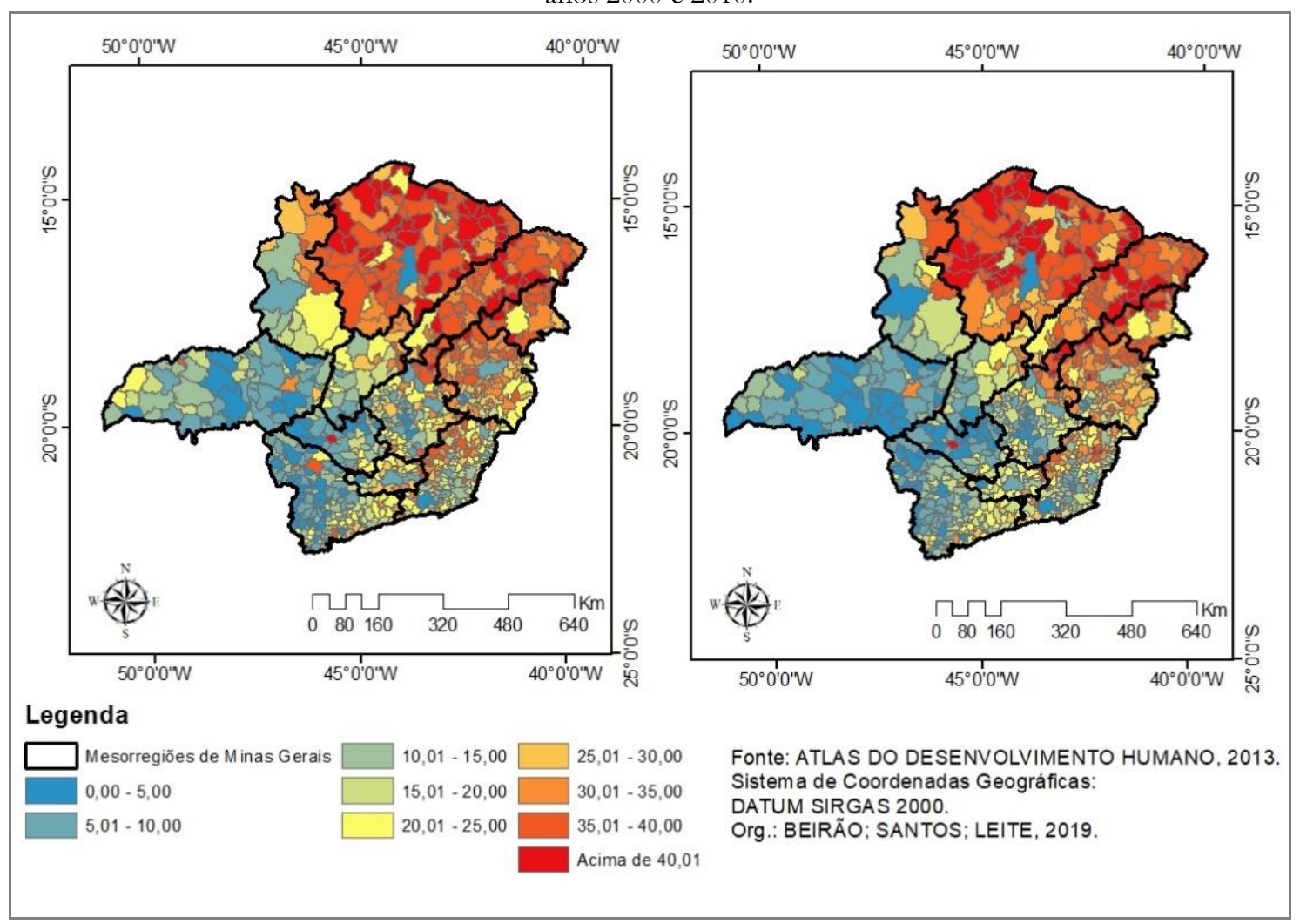

Fonte: Elaborado pelos autores com base nos dados do Atlas do Desenvolvimento Humano (2013).

A partir da análise da Figura 3 é possível observar que houve uma redução pouco significativa da porcentagem de indivíduos vulneráveis à pobreza nos municípios do estado de Minas Gerais entre os anos 2000 e 2010, visto que no ano 2000, a concentração de municípios com maior porcentagem da vulnerabilidade a esta condição localizava-se nas mesorregiões Jequitinhonha, Norte de Minas, Vale do Mucuri e Vale do Rio Doce, e no ano 2010 também. Os municípios com menores porcentagens de vulnerabilidade à condição de pobreza concentraram-se tanto no ano 2000 quanto em 2010, nas mesorregiões Central Mineira, Metropolitana de Belo Horizonte, Triângulo Mineiro/Alto Paranaíba, Sul/Sudoeste de Minas e Zona da Mata.

Se há vulnerabilidade à condição de pobreza e concentração de renda em algum território, há desigualdade na sua distribuição. O coeficiente de Gini é um indicador que mede o grau de concentração de renda em determinado grupo e aponta a diferença entre o rendimento de pobres e ricos (NEVES et al., 2015). O Coeficiente de Gini mede o grau de 
|Análise do desenvolvimento humano dos municípios do estado de Minas Gerais a partir da avaliação de indicadores socioeconômicos |

|Éder de Souza Beirão | Luíz Filipe Rodrigues dos Santos | Marcos Esdras Leite |

desigualdade na distribuição de indivíduos conforme a renda per capita. O valor deste indicador pode variar de 0 , quando não há desigualdade, a 1 , quando a desigualdade é máxima. Os indivíduos são aqueles que vivem em domicílios particulares permanentes (ATLAS DO DESENVOLVIMENTO HUMANO, 2013). A Tabela 05 apresenta o ranking dos menores coeficientes de Gini dos municípios do estado de Minas Gerais nos anos 2000 e 2010.

Tabela 05 - Ranking dos menores coeficientes de Gini dos municípios do estado de Minas Gerais nos anos 2000 e 2010.

\begin{tabular}{l|r|l|r}
\hline \multicolumn{1}{c|}{ Município } & CG/2000 & \multicolumn{1}{c|}{ Município } & CG/2010 \\
\hline Doresópolis & 0,33 & Córrego Fundo & 0,32 \\
\hline Oratórios & 0,37 & Bandeira do Sul & 0,34 \\
\hline José Gonçalves de Minas & 0,38 & Nova Serrana & 0,35 \\
\hline Carvalhópolis & 0,38 & Cachoeira Dourada & 0,35 \\
\hline Camacho & 0,39 & Perdigão & 0,35 \\
\hline Albertina & 0,39 & Albertina & 0,35 \\
\hline Santana do Riacho & 0,40 & Araújos & 0,36 \\
\hline Cedro do Abaeté & 0,40 & Piraúba & 0,37 \\
\hline Olímpio Noronha & 0,40 & Ewbank da Câmara & 0,37 \\
\hline Piranguçu & 0,41 & Japaraíba & 0,37 \\
\hline
\end{tabular}

Fonte: Elaborado pelos autores com base nos dados do Atlas do Desenvolvimento Humano (2013).

A Tabela 06 apresenta o ranking dos maiores coeficientes de Gini dos municípios do estado de Minas Gerais nos anos 2000 e 2010.

Tabela 06 - Ranking dos maiores coeficientes de Gini dos municípios do estado de Minas Gerais nos anos 2000 e 2010.

\begin{tabular}{l|r|l|r}
\hline \multicolumn{1}{c|}{ Município } & CG/2000 & \multicolumn{1}{c|}{ Município } & CG/2010 \\
\hline Novo Cruzeiro & 0,75 & Jequitibá & 0,78 \\
\hline Santa Cruz de Salinas & 0,74 & Manga & 0,68 \\
\hline Alvorada de Minas & 0,73 & Nova Lima & 0,68 \\
\hline Formoso & 0,72 & Caxambu & 0,65 \\
\hline São Gotardo & 0,72 & Salinas & 0,65 \\
\hline Centralina & 0,72 & Serro & 0,65 \\
\hline Romaria & 0,71 & Juruaia & 0,64 \\
\hline Carmo do Rio Claro & 0,71 & São João do Pacuí & 0,64 \\
\hline Chapada Gaúcha & 0,71 & Pouso Alto & 0,63 \\
\hline Passa Vinte & 0,71 & Chiador & 0,61 \\
\hline
\end{tabular}

Fonte: Elaborado pelos autores com base nos dados do Atlas do Desenvolvimento Humano (2013).

Conforme a Tabela anterior, ocorreram poucas mudanças entre os dez municípios com menores coeficientes de Gini de Minas Gerais. Apenas Albertina/MG se repetiu no ranking dos municípios com menores coeficientes de Gini nos anos 2000 e 2010. Os municípios do estado, em geral, conseguiram reduzir porcentagem de indivíduos vulneráveis à condição de pobreza. No intervalo entre os anos 2000 e 2010 não ocorreu 
|Análise do desenvolvimento humano dos municípios do estado de Minas Gerais a partir da avaliação de indicadores socioeconômicos |

|Éder de Souza Beirão | Luíz Filipe Rodrigues dos Santos | Marcos Esdras Leite |

repetições no ranking dos municípios com maiores coeficientes de Gini do estado de Minas Gerais. A Figura 4 apresenta coeficiente de Gini dos municípios do estado de Minas Gerais nos anos 2000 e 2010.

Figura 4 - Coeficiente de Gini dos municípios do estado de Minas Gerais nos anos 2000 e 2010.

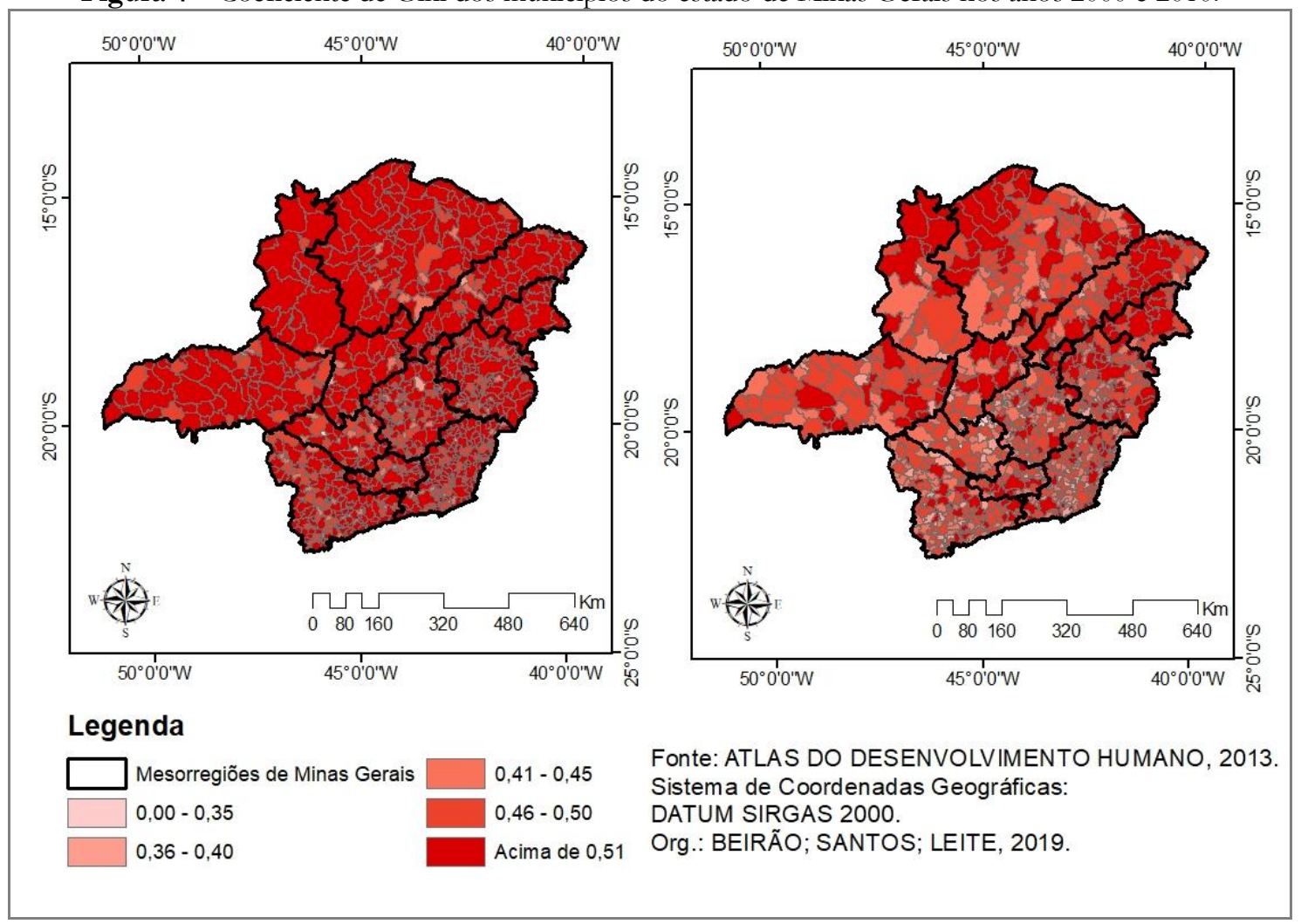

Fonte: Elaborado pelos autores com base nos dados do Atlas do Desenvolvimento Humano (2013).

A partir da análise da Figura 4 é possível observar que não houve uma redução significativa dos coeficientes de Gini nos municípios do estado de Minas Gerais entre os anos 2000 e 2010, uma vez que no ano 2000 a concentração de municípios possuidores dos maiores coeficientes localizava-se nas mesorregiões Jequitinhonha, Norte de Minas, Vale do Mucuri e Vale do Rio Doce e, no ano 2010, a situação permaneceu a mesma. Os municípios com menores coeficientes de Gini concentraram-se, tanto no ano 2000 quanto no 2010, nas mesorregiões Central Mineira, Metropolitana de Belo Horizonte, Triângulo Mineiro/Alto Paranaíba, Sul/Sudoeste de Minas e Zona da Mata.

Se há renda per capita abaixo da média, alta vulnerabilidade à condição de pobreza, há intensa desigualdade na distribuição de renda e por consequência baixa e/ou pouca qualidade de vida. Como fora mencionado anteriormente, o IDH, mais especificamente o IDH-M, representa a qualidade de vida da população de um determinado território. A Tabela 07 apresenta o ranking dos menores IDH-M dos municípios de Minas Gerais nos anos 2000 e 2010. 
|Análise do desenvolvimento humano dos municípios do estado de Minas Gerais a partir da avaliação de indicadores socioeconômicos |

|Éder de Souza Beirão | Luíz Filipe Rodrigues dos Santos | Marcos Esdras Leite |

Tabela 07 - Ranking dos menores IDH-M dos municípios do estado de Minas Gerais nos anos 2000 e 2010.

\begin{tabular}{l|r|l|r}
\multicolumn{1}{c|}{ Município } & IDH-M/2000 & \multicolumn{1}{c|}{ Município } & IDH-M/2010 \\
\hline Bonito de Minas & 0,336 & São João das Missões & 0,529 \\
\hline Fruta de Leite & 0,349 & Araponga & 0,536 \\
\hline Verdelândia & 0,358 & Bonito de Minas & 0,537 \\
\hline São João das Missões & 0,360 & Catuji & 0,540 \\
\hline Monte Formoso & 0,365 & Monte Formoso & 0,541 \\
\hline Ninheira & 0,371 & Ladainha & 0,541 \\
\hline Santo Antônio do Retiro & 0,376 & Setubinha & 0,542 \\
\hline São João do Pacuí & 0,382 & Frei Lagonegro & 0,543 \\
\hline José Raydan & 0,384 & Fruta de Leite & 0,544 \\
\hline Setubinha & 0,387 & Itaipé & 0,552 \\
\hline \multicolumn{2}{c|}{ Fonte: Elaborado pelos autores com base nos dados do Atlas do Desenvolvimento Humano $(2013)}$.
\end{tabular}

A Tabela 08 apresenta o ranking dos maiores IDH-M dos municípios do estado de Minas Gerais nos anos 2000 e 2010.

Tabela 08 - Ranking dos maiores IDH-M dos municípios do estado de Minas Gerais nos anos 2000 e 2010.

\begin{tabular}{l|r|l|r}
\hline \multicolumn{1}{c|}{ Município } & IDH-M/2000 & \multicolumn{1}{c|}{ Município } & IDH-M/2010 \\
\hline Belo Horizonte & 0,726 & Nova Lima & 0,813 \\
\hline Poços de Caldas & 0,716 & Belo Horizonte & 0,810 \\
\hline Juiz de Fora & 0,703 & Uberlândia & 0,789 \\
\hline Uberlândia & 0,702 & Itajubá & 0,787 \\
\hline Varginha & 0,702 & Lavras & 0,782 \\
\hline São Lourenço & 0,699 & Poços de Caldas & 0,779 \\
\hline Timóteo & 0,695 & Varginha & 0,778 \\
\hline Uberaba & 0,692 & Juiz de Fora & 0,778 \\
\hline Itajubá & 0,691 & Lagoa Santa & 0,777 \\
\hline Pouso Alegre & 0,690 & Itaú de Minas & 0,776 \\
\hline
\end{tabular}

Fonte: Elaborado pelos autores com base nos dados do Atlas do Desenvolvimento Humano (2013).

Conforme a Tabela anterior, ocorreram poucas mudanças entre os dez municípios com menor IDH-M de Minas Gerais. Muitas cidades se repetiram no ranking dos municípios com menor IDH-M em Minas Gerais nos anos 2000 e 2010, dentre eles, Bonito de Minas/MG, Fruta de Leite/MG, São João das Missões/MG e Monte Formoso/MG. Apesar disso, todos os outros mudaram de posição, com exceção do município de Monte Formoso/MG, no intervalo do ano 2000 para o ano 2010. No ano 2000, os municípios de Bonito de Minas/MG, Fruta de Leite/MG e São João das Missões/MG ocupavam a primeira, segunda e quarta posição, respectivamente, entre os municípios com menores IDH-M do estado de Minas Gerais. Já no ano 2010, os mesmos municípios ocuparam a terceira, nona e primeira posições, respectivamente. Os municípios do estado, em geral, conseguiram elevar seus índices de desenvolvimento humano municipal, indicando que houve uma melhora na qualidade de vida nos habitantes dos municípios deste estado. 
|Análise do desenvolvimento humano dos municípios do estado de Minas Gerais a partir da avaliação de indicadores socioeconômicos |

|Éder de Souza Beirão | Luíz Filipe Rodrigues dos Santos | Marcos Esdras Leite |

No intervalo entre os anos 2000 e 2010 ocorreu uma repetição no ranking dos municípios com maiores IDH-M do estado de Minas Gerais, dentre eles, Belo Horizonte/MG, Poços de Caldas/MG, Juiz de Fora/MG, Uberlândia/MG e Varginha/MG. Estes municípios mudaram de posição neste intervalo de tempo, tendo ocupado no ano 2000, a primeira, segunda, terceira, quarta e quinta posições, e no ano 2010 passaram a ocupar a segunda, sexta, oitava, terceira e sétima posições, respectivamente. A Figura 5 apresenta o IDH-M dos municípios de Minas Gerais nos anos 2000 e 2010.

Figura 5 - IDH-M dos municípios do estado de Minas Gerais nos anos 2000 e 2010.

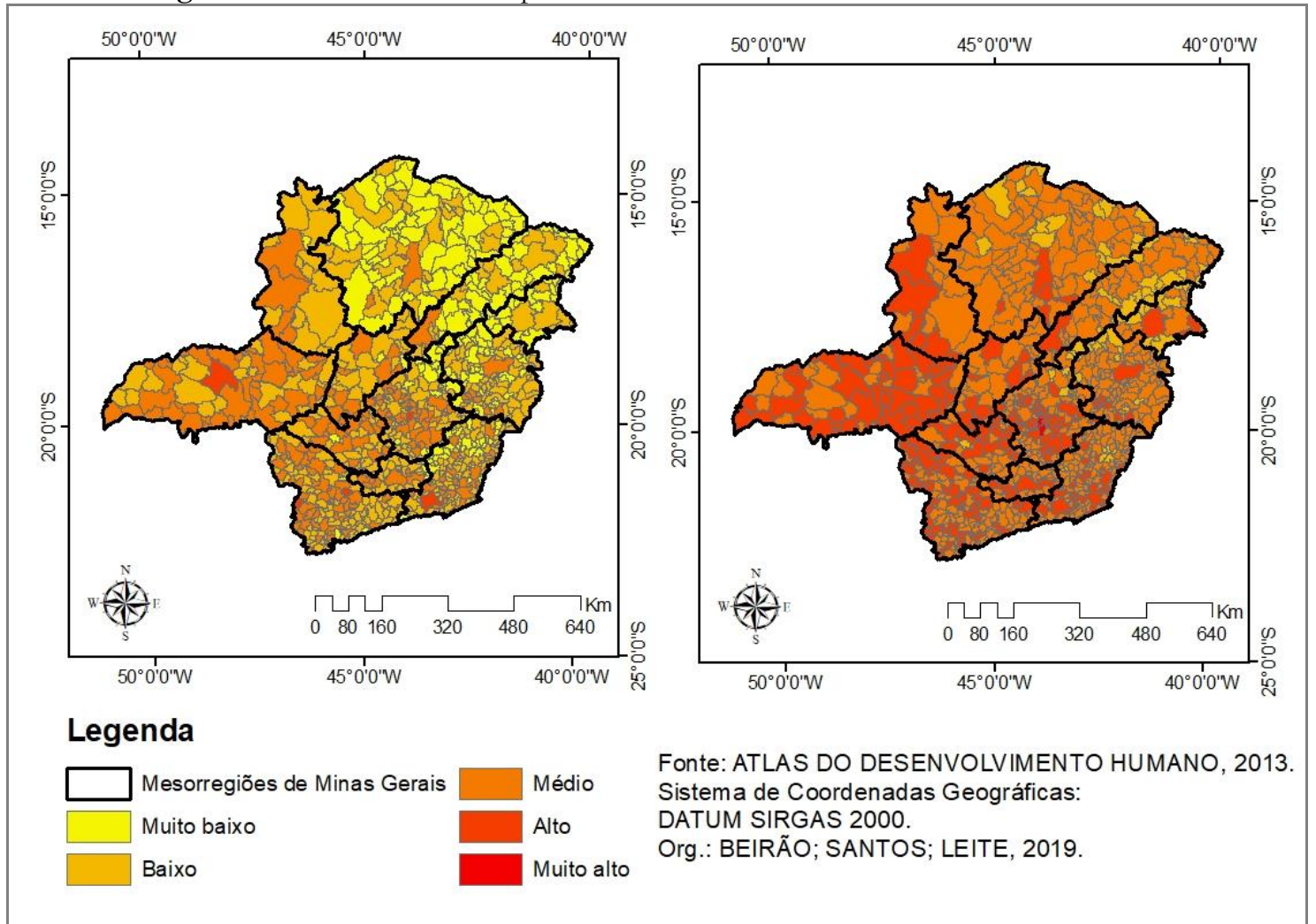

Fonte: Elaborado pelos autores com base nos dados do Atlas do Desenvolvimento Humano (2013).

A partir da análise da Figura anterior é possível observar que houve uma elevação significativa do IDH-M nos municípios do estado de Minas Gerais no intervalo entre os anos 2000 e 2010, visto que no primeiro, a concentração de municípios com menores indicadores encontrava-se localizada nas mesorregiões Jequitinhonha, Norte de Minas, Vale do Mucuri e Vale do Rio Doce e no ano 2010 a situação do estado se modificou, visto que o IDH-M se elevou consideravelmente em todas as mesorregiões do estado, tendo quase que uniformizado os estratos do indicador. A melhoria do IDH-M pode ter ocorrido em razão da melhoria das condições de saúde, educação e renda da população dos municípios. 
|Análise do desenvolvimento humano dos municípios do estado de Minas Gerais a partir da avaliação de indicadores socioeconômicos |

|Éder de Souza Beirão | Luíz Filipe Rodrigues dos Santos | Marcos Esdras Leite |

A melhoria das condições é considerada parte fundamental do processo de desenvolvimento (SCARPIN; SLOMSKI, 2007).

O IDH-M é subdivido em três dimensões: Renda, Longevidade e Educação. Como a primeira dimensão já fora abordada na análise da renda per capita dos municípios do estado nos anos 2000 e 2010, este estudo versará agora sobre as dimensões Longevidade e Educação do IDH-M. A Tabela 09 apresenta o ranking dos menores IDH-M Longevidade dos municípios do estado de Minas Gerais no mesmo período.

Tabela 09 - Ranking dos menores IDH-M Longevidade dos municípios do estado de Minas Gerais nos anos 2000 e 2010.

\begin{tabular}{|c|c|c|c|}
\hline Município & IDH-ML/2000 & Município & IDH-ML/2010 \\
\hline Santa Helena de Minas & 0,627 & Santa Helena de Minas & 0,723 \\
\hline Setubinha & 0,642 & Divisa Alegre & 0,723 \\
\hline Frei Lagonegro & 0,653 & Palmópolis & 0,738 \\
\hline Mata Verde & 0,653 & Pedra Bonita & 0,740 \\
\hline Santa Cruz de Salinas & 0,653 & Setubinha & 0,743 \\
\hline Angelândia & 0,654 & Felisburgo & 0,744 \\
\hline Cipotânea & 0,659 & Imbé de Minas & 0,744 \\
\hline Curral de Dentro & 0,662 & Pingo d'Água & 0,744 \\
\hline Santa Maria do Salto & 0,662 & Congonhas do Norte & 0,746 \\
\hline Novo Oriente de Minas & 0,666 & Frei Lagonegro & 0,749 \\
\hline
\end{tabular}

Já a Tabela 10 apresenta o ranking dos maiores IDH-M Longevidade dos municípios do estado de Minas Gerais nos anos 2000 e 2010.

Tabela 10 - Ranking dos maiores IDH-M Longevidade dos municípios do estado de Minas Gerais nos anos 2000 e 2010.

\begin{tabular}{l|r|l|r}
\hline \multicolumn{1}{c|}{ Município } & IDH-ML/2000 & \multicolumn{1}{c|}{ Município } & IDH-ML/2010 \\
\hline Poços de Caldas & 0,850 & Passos & 0,886 \\
\hline Andradas & 0,840 & Nova Lima & 0,885 \\
\hline Montes Claros & 0,840 & Tiradentes & 0,885 \\
\hline Pitangui & 0,837 & Uberlândia & 0,885 \\
\hline São Lourenço & 0,836 & Itajubá & 0,884 \\
\hline Campina Verde & 0,830 & Viçosa & 0,883 \\
\hline Frutal & 0,830 & Barbacena & 0,881 \\
\hline Nova Serrana & 0,830 & Lavras & 0,880 \\
\hline Carmo do Paranaíba & 0,829 & Perdizes & 0,880 \\
\hline Laranjal & 0,829 & Guaxupé & 0,880 \\
\hline
\end{tabular}

Fonte: Elaborado pelos autores com base nos dados do Atlas do Desenvolvimento Humano (2013).

Observa-se nessa Tabela que ocorreram poucas mudanças entre os dez municípios com menor IDH-M Longevidade no estado. Poucas cidades se repetiram no ranking dos municípios com menor IDH-M Longevidade em Minas Gerais nos anos 2000 e 2010, dentre eles, Santa Helena de Minas/MG, Setubinha/MG e Frei Lagonegro/MG. Todos 
|Análise do desenvolvimento humano dos municípios do estado de Minas Gerais a partir da avaliação de indicadores socioeconômicos |

|Éder de Souza Beirão | Luíz Filipe Rodrigues dos Santos | Marcos Esdras Leite |

estes municípios mudaram de posição, com exceção do município de Santa Helena de Minas/MG, no intervalo do ano 2000 para o ano 2010. No ano 2000, os municípios de Setubinha/MG e Frei Lagonegro/MG ocupavam a primeira e segunda posições, respectivamente, entre os municípios com menores IDH-M Longevidade do estado de Minas Gerais. Já no ano 2010, os mesmos municípios ocuparam quinta e décima posições, respectivamente. Os municípios do estado de Minas Gerais, no geral, conseguiram elevar seus IDH-M Longevidade, no intervalo entre os anos 2000 e 2010, indicando que além de uma melhoria na qualidade de vida, os habitantes dos municípios deste estado vivem mais e com mais saúde. A Figura 6 apresenta o IDH-M Longevidade dos municípios do estado de Minas Gerais nos anos 2000 e 2010.

Figura 6 - IDH-M Longevidade dos municípios do estado de Minas Gerais nos anos 2000 e 2010.

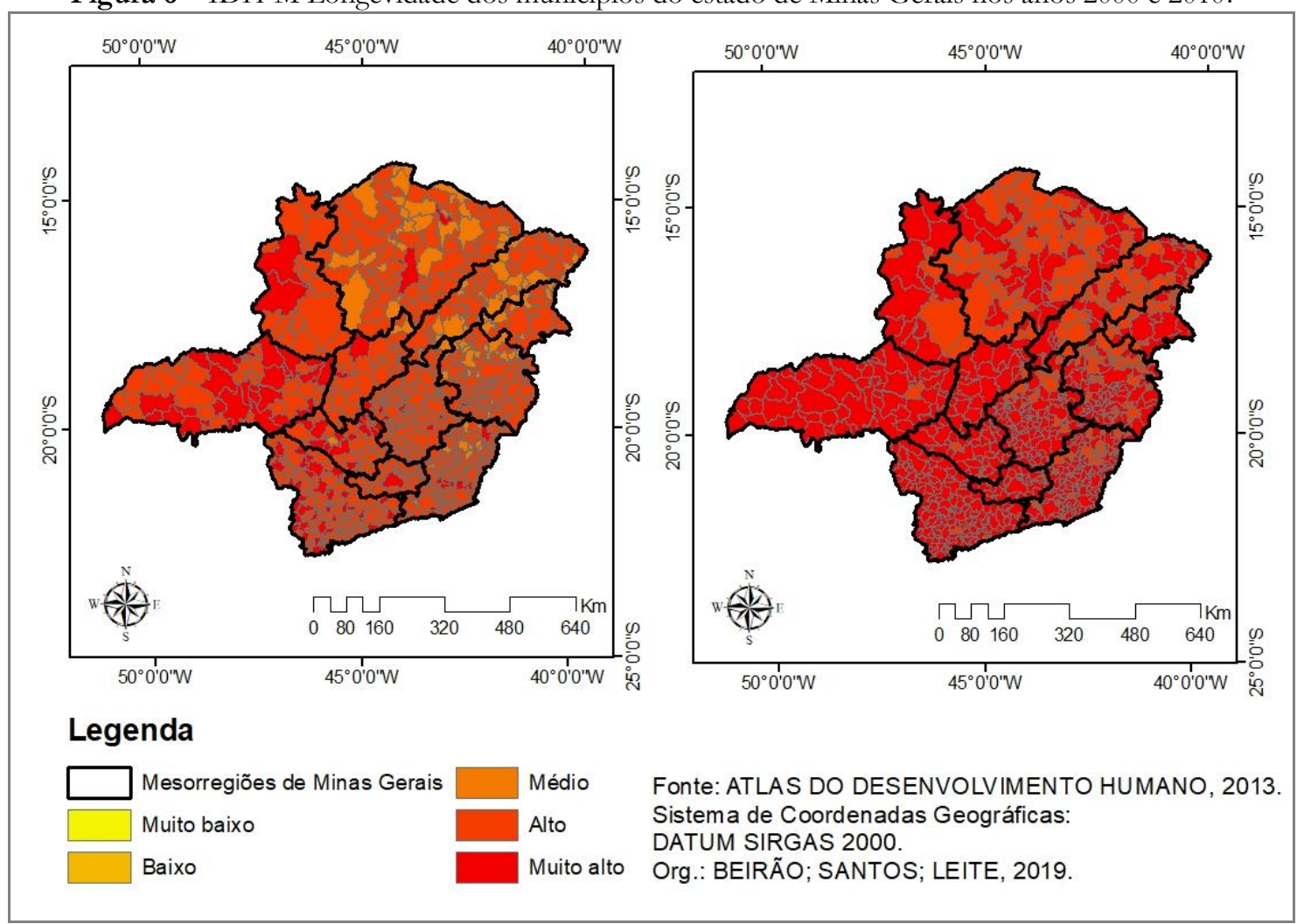

Fonte: Elaborado pelos autores com base nos dados do Atlas do Desenvolvimento Humano (2013).

A partir da análise dessa Figura é possível observar que houve um aumento pouco significativo do IDH-M Longevidade nos municípios do estado de Minas Gerais entre os anos 2000 e 2010, visto que, no primeiro ano, a concentração de municípios com os menores extratos do indicador localizava-se nas mesorregiões Jequitinhonha, Norte de Minas, Vale do Mucuri e Vale do Rio Doce e no ano 2010 também. Os municípios com maiores extratos do IDH-M Longevidade concentraram-se, tanto no ano 2000 quanto no 
|Análise do desenvolvimento humano dos municípios do estado de Minas Gerais a partir da avaliação de indicadores socioeconômicos |

|Éder de Souza Beirão | Luíz Filipe Rodrigues dos Santos | Marcos Esdras Leite |

2010, nas mesorregiões Central Mineira, Metropolitana de Belo Horizonte, Triângulo Mineiro/Alto Paranaíba, Sul/Sudoeste de Minas e Zona da Mata.

A Tabela 11 apresenta o ranking dos menores IDH-M Educação dos municípios do estado de Minas Gerais nos anos 2000 e 2010.

Tabela 11 - Ranking dos menores IDH-M Educação dos municípios do estado de Minas Gerais nos anos 2000 e 2010.

\begin{tabular}{l|r|l|r}
\hline \multicolumn{1}{c|}{ Município } & IDH-ME/2000 & \multicolumn{1}{c|}{ Município } & IDH-ME/2010 \\
\hline Ninheira & 0,143 & Araponga & 0,339 \\
\hline Fruta de Leite & 0,145 & Fruta de Leite & 0,370 \\
\hline Bonito de Minas & 0,148 & Sericita & 0,375 \\
\hline São João das Missões & 0,150 & Nacip Raydan & 0,377 \\
\hline Verdelândia & 0,151 & Senhora do Porto & 0,378 \\
\hline Monte Formoso & 0,164 & São João das Missões & 0,381 \\
\hline José Raydan & 0,167 & Catuji & 0,382 \\
\hline Araponga & 0,181 & Bonito de Minas & 0,388 \\
\hline São João do Pacuí & 0,181 & Itaipé & 0,388 \\
\hline Santo Antônio do Retiro & 0,182 & Rio Vermelho & 0,389 \\
\hline
\end{tabular}

Fonte: Elaborado pelos autores com base nos dados do Atlas do Desenvolvimento Humano (2013).

A Tabela 12 apresenta o ranking dos maiores IDH-M Educação dos municípios do estado de Minas Gerais nos anos 2000 e 2010.

Tabela 12 - Ranking dos maiores IDH-M Educação dos municípios do estado de Minas Gerais nos anos 2000 e 2010.

\begin{tabular}{|c|c|c|c|}
\hline Município & IDH-ME/2000 & Município & IDH-ME/2010 \\
\hline Belo Horizonte & 0,617 & Monte Sião & 0,744 \\
\hline Ouro Branco & 0,601 & Timóteo & 0,742 \\
\hline Timóteo & 0,598 & Belo Horizonte & 0,737 \\
\hline Juiz de Fora & 0,594 & Lavras & 0,719 \\
\hline Itajubá & 0,587 & Itajubá & 0,718 \\
\hline Uberlândia & 0,587 & Araguari & 0,716 \\
\hline Ipatinga & 0,583 & Uberlândia & 0,716 \\
\hline Araxá & 0,582 & Alfenas & 0,712 \\
\hline Varginha & 0,580 & Confins & 0,711 \\
\hline Grupiara & 0,575 & Itaú de Minas & 0,711 \\
\hline
\end{tabular}

Foram observadas poucas mudanças entre os dez municípios com menor IDH-M Educação de Minas Gerais. Algumas das cidades se repetiram no ranking dos municípios com menor IDH-M Educação em Minas Gerais nos anos 2000 e 2010, dentre eles, Fruta de Leite/MG, São João das Missões/MG e Araponga/MG. Apesar disso, todos mudaram de posição no intervalo do ano 2000 para o ano 2010, com exceção de Fruta de Leite/MG. No ano 2000, os municípios de São João das Missões/MG e Araponga/MG ocupavam a quarta e oitava posições, respectivamente, entre os municípios com menores IDH-M 
|Análise do desenvolvimento humano dos municípios do estado de Minas Gerais a partir da avaliação de indicadores socioeconômicos |

|Éder de Souza Beirão | Luíz Filipe Rodrigues dos Santos | Marcos Esdras Leite |

Educação do estado. Já no ano 2010, os mesmos municípios ocuparam a sexta e primeira posições, respectivamente. Assim, os municípios do estado apresentaram melhora na qualidade de vida dos habitantes dos municípios deste estado, sobretudo no acesso aos serviços de educação, através do aumento de matrículas e na alfabetização.

No intervalo entre os anos 2000 e 2010 ocorreu uma repetição no ranking dos municípios com maiores IDH-M Educação do estado de Minas Gerais, dentre eles, Belo Horizonte/MG, Timóteo/MG, Itajubá/MG e Uberlândia/MG. Estes municípios mudaram de posição neste intervalo de tempo, com exceção de Itajubá/MG. No ano 2000, os municípios de Belo Horizonte/MG, Timóteo/MG e Uberlândia/MG ocupavam a primeira, terceira e sexta posições, respectivamente, entre os municípios com maiores IDH-M Educação do estado. Já no ano 2010, os mesmos municípios ocuparam a terceira, segunda e sétima posições, respectivamente. A Figura 7 apresenta IDH-M Educação dos municípios nos anos 2000 e 2010.

Figura 7 - IDH-M Educação dos municípios do estado de Minas Gerais nos anos 2000 e 2010.

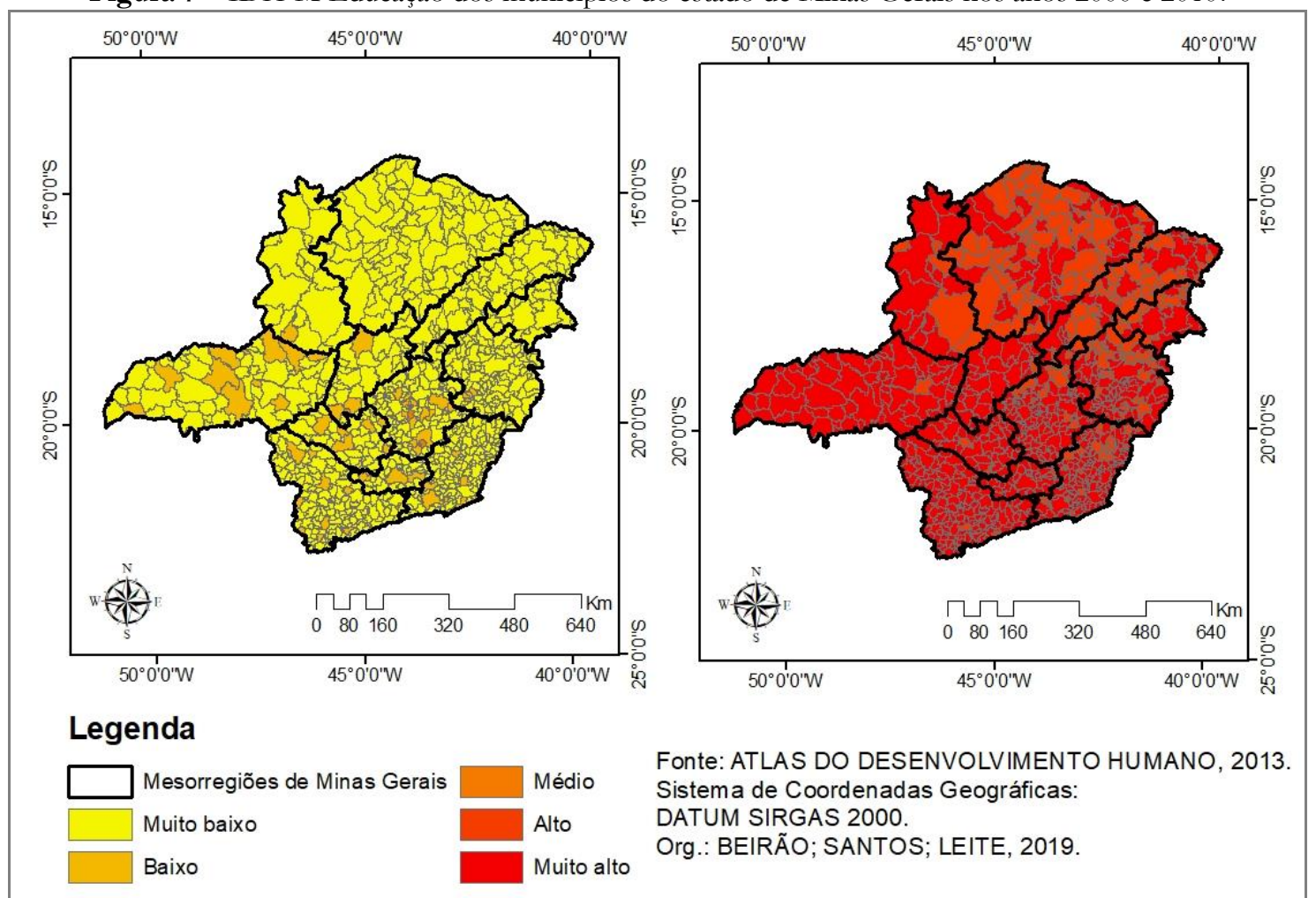

Fonte: Elaborado pelos autores com base nos dados do Atlas do Desenvolvimento Humano (2013).

A partir da análise da Figura anterior é possível observar que houve uma elevação muito significativa do IDH-M Educação nos municípios de Minas Gerais entre os anos 2000 e 2010, visto que no ano 2000 a maioria dos municípios apresentou o menor extrato do indicador. No ano 2010, a situação se modificou, indicando que o estado experimentou uma elevação na oferta de seus serviços de educação, da alfabetização de seus habitantes e 
|Análise do desenvolvimento humano dos municípios do estado de Minas Gerais a partir da avaliação de indicadores socioeconômicos |

|Éder de Souza Beirão | Luíz Filipe Rodrigues dos Santos | Marcos Esdras Leite |

do número de matrículas nas escolas, resultando na melhoria do acesso à educação nos municípios mineiros.

\section{CONSIDERAÇÕES FINAIS}

A fundamental discussão de Furtado (1974) ainda é atual para interpretação do desenvolvimento dos países centrais e periféricos. A universalização do desenvolvimento, colocando-o como processo igual em todas as sociedades foi desmitificada pelo economista. Assim, é possível perceber as diferenças em termos de desenvolvimento nos países centrais, em comparação aos países periféricos. Se a universalização não ocorre equiparando países, ela evidencia discrepâncias notáveis quando é analisado internamente um país desigual como o Brasil.

No caso específico do Brasil, de acordo com Cano (1985, p. 29), observa-se que nas regiões industrializadas “a qualidade de vida baixou consideravelmente: ganharam mais indústrias e mais empregos, mas também ganharam mais filas de transporte, menos água, escolas e hospitais (...) e muito mais favelas". Sabemos que o desenvolvimento se difere nas regiões brasileiras, e quando se trata do estado de Minas Gerais, prontamente verifica-se um recorte de desigualdades socioeconômicas e regionais.

Como já discutido, Minas possui maior número de municípios no país, mas também apresenta enormes diferenças em termos de IDH-M dentre os municípios. As mesorregiões Central Mineira e Sul/Sudoeste de Minas concentram municípios com índices ideais, mas na mesorregião Norte de Minas, esses números diminuem, expressando avanços desiguais do desenvolvimento capitalista nas regiões. De um lado, as regiões Central Mineira e Sul/Sudoeste de Minas possuem maior industrialização e avanço capitalista, ao contrário da segunda região citada que apresenta uma tímida industrialização. Mas é claro, industrialização é somente uma das variáveis do desenvolvimento, questões climáticas, geográficas, dentre outras, são fundamentais nesse processo.

O estudo teve como objetivo geral analisar o desenvolvimento humano dos municípios do estado de Minas Gerais a partir da avaliação de indicadores socioeconômicos. O objetivo fora alcançado, uma vez que foi possível analisar a situação social e econômica e do desenvolvimento humano, além de realizar uma breve caracterização socioeconômica dos municípios do estado de Minas Gerais nos anos 2000 e 2010 a partir da análise do IDH-M, suas dimensões Longevidade (IDH-M Longevidade) e Educação (IDH-M Educação), em conjunto com os indicadores escolhidos, que foram o 
|Análise do desenvolvimento humano dos municípios do estado de Minas Gerais a partir da avaliação de indicadores socioeconômicos |

|Éder de Souza Beirão | Luíz Filipe Rodrigues dos Santos | Marcos Esdras Leite |

PIB per capita (proxy da renda per capita), a porcentagem de indivíduos vulneráveis à pobreza e o coeficiente de Gini (concentração de renda/desigualdade na distribuição da mesma).

Os indicadores utilizados foram devidamente definidos e contextualizados e posteriormente foi realizada a consecução de mapas para a realização de uma melhor caracterização dos municípios do estado de Minas Gerais nos anos 2000 e 2010.

Foi possível identificar através da análise que houve uma melhora geral em todos os indicadores utilizados, sendo que para alguns a melhoria foi significativa e para outros pouco considerável. Ocorre que, apesar desta melhora geral, as situações adversas persistem impedindo que os habitantes dos municípios do estado de Minas Gerais tenham uma maior qualidade de vida e, portanto, tenham um melhor desempenho no que tange ao desenvolvimento humano.

Conclui-se a partir da análise deste conjunto de indicadores que a qualidade de vida, representada pelo IDH-M e suas dimensões, é afetada pelos indicadores socioeconômicos escolhidos para esta análise, pois foi possível chegar à conclusão de que a redução da renda per capita leva ao aumento da vulnerabilidade social e consequente elevação da desigualdade na distribuição de renda (concentração de renda). Estes fatores interferem na qualidade de vida dos habitantes dos municípios do estado de Minas Gerais, principalmente no que tange às dimensões da saúde e educação, representadas pelo IDH-M Longevidade e Educação, respectivamente.

\section{REFERÊNCIAS}

ALMEIDA, Vinícius Pacheco; OLIVEIRA, Édivo de Almeida. Uma análise de indicadores: uma caracterização e mapeamento do desenvolvimento humano dos municípios do Rio Grande do Sul. In: ENCONTRO DE ECONOMIA GAÚCHA, 8., 2016, Porto Alegre. Anais... Porto Alegre, 2016.

ATLAS DO DESENVOLVIMENTO HUMANO. Atlas de Desenvolvimento Humano no Brasil. Brasília: PNUD, 2013. Disponível em: < http://atlasbrasil.org.br/2013/>. Acesso em: 10 jul. 2019.

CANO, Wilson. Desequilíbrios regionais e concentração de renda no Brasil: 19301970. São Paulo: Globo, 1985.

ENVIRONMENTAL SYSTEMS RESEARCH INSTITUTE. Esri ArcGIS. Versão 10.5 [software], 2020. Disponível em: <https://www.esri.com/pt-br/arcgis/products/arcgisonline/overview>. Acesso em: 10 jul. 2019.

FURTADO, Celso. O mito do desenvolvimento econômico. São Paulo: Círculo do Livro, 1974. 
|Análise do desenvolvimento humano dos municípios do estado de Minas Gerais a partir da avaliação de indicadores socioeconômicos |

|Éder de Souza Beirão | Luíz Filipe Rodrigues dos Santos | Marcos Esdras Leite |

GONÇALVES, Solange Ledi; MACHADO, Ana Flávia. Vulnerabilidade das famílias à pobreza: uma análise empírica para seis regiões metropolitanas (2002 a 2011). In: ENCONTRO NACIONAL DE ECONOMIA DA ASSOCIAÇÃO NACIONAL DE CENTROS DE PÓS-GRADUAÇÃO EM ECONOMIA, 42., 2013, Foz do Iguaçu. Anais... Foz do Iguaçu: ANPEC, 2013.

FUNDAÇÃO JOÃO PINHEIRO. Índice Mineiro de Responsabilidade Social. Belo Horizonte: FJP, 2019. Disponível em: < http://imrs.fip.mg.gov.br/>. Acesso em: 28 ago. 2019.

JANNUZZI, Paulo de Martino. Indicadores sociais no Brasil. Campinas: Alínea, 2001.

JANNUZZI, Paulo de Martino. Indicadores socioeconômicos na gestão pública. 2. ed. Florianópolis: Departamento de Ciências da Administração/UFSC, 2012.

LIMA, Severino Cesário de; DINIZ, Josedilton Alves. Contabilidade Pública: análise financeira governamental. São Paulo: Atlas, 2016.

MARTINS, Clitia Helena Backx. Pobreza, meio ambiente e qualidade de vida: indicadores para o desenvolvimento humano sustentável. Ind. Econ. FEE, v. 30, n. 3, p. 171-188, 2002.

MOLDAU, Juan Hersztajn. Os fundamentos microeconômicos dos indicadores de desenvolvimento socioeconômico. Revista de Economia Política, v. 18, n. 3 (71), jul./set. 1998.

MONTEIRO, Márcio Andrade. A matemática do Índice de Desenvolvimento Humano IDH. Revista do Professor de Matemática, v. 67, set./dez. 2008.

MICROSOFT. Excel. Versão 10 [software], 2020. Disponível em: <https://www.microsoft.com/pt-br>. Acesso em: 10 jul. 2019.

MINAYO, Maria Cecília de Souza; HARTZ, Zulmira Maria de Araújo; BUSS, Paulo Marchiori. Qualidade de vida e saúde: um debate necessário. Ciência \& Saúde Coletiva, v. 5, n. 1, p. 7-18, 2000.

NEVES, Cleverson [et al.]. Análise do Índice de Gini nos municípios de Santa Catarina em 2000 e 2010: uma abordagem exploratória de dados espaciais. Revista Brasileira de Estudos Regionais e Urbanos - RBERU, v. 09, n. 2, p. 209-227, 2015.

OLIVEIRA, Gilson Batista de. Uma discussão sobre o conceito de desenvolvimento. Rev. FAE, Curitiba, v. 5, n. 2, p. 37-48, 2002.

ORLOWSKI, Rosemari Fátima; AREND, Silvio Cezar. Indicadores de desenvolvimento socioeconômico na região da AMOSC - Associação dos Municípios do Oeste de Santa Catarina. In: CONGRESSO DA SOCIEDADE BRASILEIRA DE ECONOMIA, ADMINISTRAÇÃO E SOCIOLOGIA RURAL, 43., 2005, Ribeirão Preto. Anais eletrônicos... Ribeirão Preto: SOBER, 2005. Disponível em: < http://www.sober.org.br/palestra/2/922.pdf>. Acesso em: 19 jul. 2019.

OSÓRIO, Rafael Guerreiro [et al.]. Perfil de pobreza no Brasil e sua evolução no período 2004-2009. Brasília/DF: IPEA, 2011. (Texto para Discussão, n. 1647). Disponível 
|Análise do desenvolvimento humano dos municípios do estado de Minas Gerais a partir da avaliação de indicadores socioeconômicos |

|Éder de Souza Beirão | Luíz Filipe Rodrigues dos Santos | Marcos Esdras Leite |

em: <http://www.ipea.gov.br/portal/images/stories/PDFs/TDs/td 1647.pdf $>$. Acesso em: 11 jul. 2019.

PROGRAMA DAS NAÇÕES UNIDAS PARA O DESENVOLVIMENTO. Atlas do Desenvolvimento Humano do Brasil. Brasilia: PNUD/Ipea/FJP, 2013. Disponível em: $<$ http://www.atlasbrasil.org.br/2013/pt/consulta $>$. Acesso em: 12 ago. 2019.

PROGRAMA DAS NAÇÕES UNIDAS PARA O DESENVOLVIMENTO. Desenvolvimento Humano e IDH. Rio de Janeiro: PNUD, 2019.

PROGRAMA DAS NAÇÕES UNIDAS PARA O DESENVOLVIMENTO. Relatório sobre desenvolvimento humano no Brasil. Rio de Janeiro: IPEA/PNUD, 1996.

RODRIGUES, Maria Cecília Prates. O índice do desenvolvimento humano (IDH) da ONU. Revista Conjuntura Econômica, Rio de Janeiro, v. 47, n. 7, jul. 1993.

SANDRONI, Paulo. Dicionário de economia. São Paulo: Atlas, 1994.

SCARPIN, Jorge Eduardo; SLOMSKI, Valmor. Estudo dos fatores condicionantes do Índice de Desenvolvimento Humano nos municípios do estado do Paraná: um instrumento de controladoria para a tomada de decisões na gestão governamental. Revista de Administração Pública, v. 41, n. 5, p. 909-33, set./out. 2007.

SEN, Amartya. Desenvolvimento como liberdade. São Paulo: Companhia das Letras, 2000.

SEN, Amartya. Desigualdade reexaminada. Rio de Janeiro: Record, 2001.

SIEDENBERG, Dieter Rugard. Indicadores de desenvolvimento socioeconômico: uma síntese. Revista Desenvolvimento em Questão, v. 1, n. 1, p. 45-71, 2003.

VASCONCELOS, Marco Antônio; GARCIA, Manuel Enriquez. Fundamentos de economia. São Paulo: Saraiva, 1998.

Como citar este artigo:

\section{ABNT}

BEIRÃO, É. S.; SANTOS, L. F. R.; LEITE, M. E. Análise do desenvolvimento humano dos municípios do estado de Minas Gerais a partir da avaliação de indicadores socioeconômicos. InterEspaço: Revista de Geografia e Interdisciplinaridade, v. 6, e202027, 2020. Disponível em: <http://dx.doi.org/10.18764/2446-6549.e202027>. Acesso em: 25 jan. 2020.

\section{APA:}

Beirão, É. S.; Santos, L. F. R.; \& Leite, M. E. (2020). Análise do desenvolvimento humano dos municípios do estado de Minas Gerais a partir da avaliação de indicadores socioeconômicos. InterEspaço: Revista de Geografia e Interdisciplinaridade, v. 6, e202027. Recuperado em 25 janeiro, 2020, de http://dx.doi.org/10.18764/2446-6549.e202027 
|Análise do desenvolvimento humano dos municípios do estado de Minas Gerais a partir da avaliação de indicadores socioeconômicos |

|Éder de Souza Beirão | Luíz Filipe Rodrigues dos Santos | Marcos Esdras Leite |

\section{cc) creative}

This is an open access article under the CC BY Creative Commons 4.0 license.

Copyright (C) 2020, Universidade Federal do Maranhão.

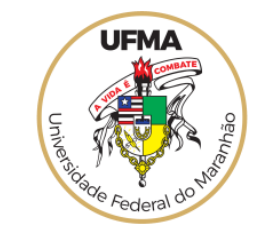

